\title{
MS009.P54
}

\section{Architecture of $\beta$-D-galactosidase active site as basis for enzyme engineering}

Maria Zofia Rutkiewicz-Krotewicz ${ }^{1}$, Anna Bujacz ${ }^{1}$, Marta Wanarska ${ }^{2}$, Hubert Cieslinski ${ }^{2}$

${ }^{1}$ Institute Of Technical Biochemistry, Lodz University Of Technology, Lodz, Poland, ${ }^{2}$ Microbiology Department, Gdansk University of Technology, Gdansk, Poland

E-mail: maria.rutkiewicz-krotewicz@dokt.p.lodz.pl

$\beta$-D-galactosidases ( $\beta D G)$ are enzymes widely used in food industry to hydrolyze, naturally occurring in milk, lactose. Removal of this disaccharide benefits organoleptic characteristics of milk and dairy products by improving its sweetness and preventing "sand effect", which is especially important for texture quality of condensed milk and ice-creams. The milk with depleted level of lactose, or lactose-free one, is being used in production of some cheese species. Additionally, lactose-free products are classified as special nutrition products for people suffering from lactose intolerance. [1]

For the removal of lactose in food industry, a mesophilic $\beta D G$ from Kluyveromyces lactis, which optimal temperature is $50^{\circ} \mathrm{C}$, is being used. [2] However, replacing it with a cold-adapted enzyme e.g. BDG from Arthrobacter sp. 32cB [3], which is able to hydrolyze lactose at $10{ }^{\circ} \mathrm{C}$ with $\mathrm{KM} 16.56 \mathrm{mM}$ and kcat $31.84 \mathrm{~s}-1$, would lead to a number of advantages such as: hydrolysis of lactose during transport or storage of product, lowering the risk of mesophilic contamination (no heating of milk would be necessary), eliminating the risk of formation of unwanted products of thermal conversions, and lowering the production costs by cutting heating costs.

ArthßDG is especially interesting due to its natural transglycosylation activity - it may be used for converting of unwanted lactose into desired GOS and HOS such as lactulose - used especially in infant nourishment.

The diffraction data of complexes of ArthßDG with ligands, from crystals obtained by cocrystallization, were collected on BL14.2 line of BESSY Berlin, Germany. The data of ArthßDG complexes with: galactose, IPTG, ONPG and sucrose were processed in trigonal space group P31 21 up to the resolution of $2.1 \AA, 2.2 \AA, 2.8 \AA$ and $1.9 \AA$, respectively. Crystal structures were solved by molecular replacement using the native structure of Arth $\beta D G$ as a model. Obtained crystal structures of ArthßDG complexes enabled characterization of the active site and determining residues that take part in substrate biding.

Determination of elements responsible for cold-adaptation and catalytically important residues will enable engineering of cold-adapted enzyme with enhanced transglycosylation activity.

This research was supported by grant 2016/21/B/ST5?00555 from the National Science Centre.

[1] Rutkiewicz-Krotewicz M., Pietrzyk-Brzezinska A., Sekula B., Ciesliński H, Wierzbicka-Wos A., Kur J., Bujacz A. (2016) Acta Cryst. D 72, 1049-1061

[2] Kim C. S., Ji E. S., Oh D. K. (2003) Biotechnol Lett. 25, 1769-1774

[3] Pawlak-Szukalska A., Wanarska M., Popinigis A. T., Kur J. (2014) Process Biochemistry 49, 2122-2133

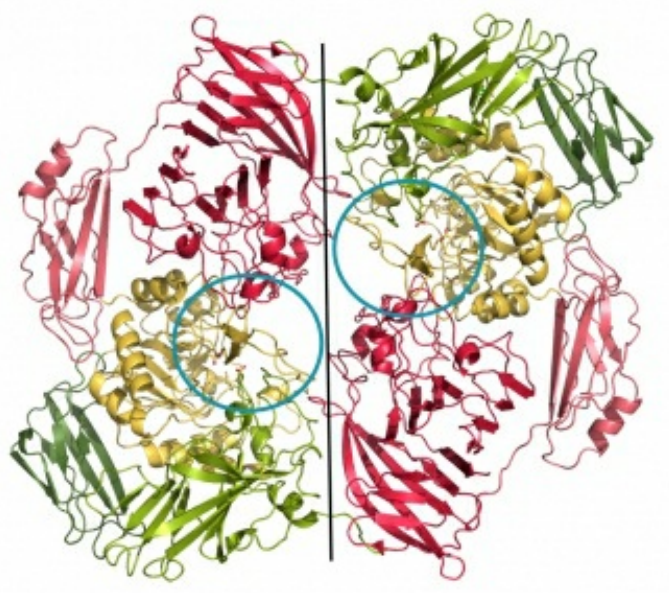

Keywords: galactosidase, cold-adapted, transglycosylation 